Revista de Derecho de la Pontificia Universidad Católica de Valparaíso XXXVI (Valparaíso, Chile, 2011, $1^{\text {er }}$ Semestre) [pp. 251 - 277]

\title{
LOS PROCESOS ADMINISTRATIVOS EN EL DERECHO CHILENO*
}

\author{
["Administrative Processes in the Chilean Law"]
}

\author{
Juan Carlos Ferrada Bórquez ${ }^{* *}$ \\ Universidad de Valparaíso, Chile
}

\begin{abstract}
RESUMEN
En este trabajo se realiza un análisis de los procesos a través de los cuales se desarrolla la justicia administrativa en el Derecho chileno. Para ello se parte de una distinción entre procedimientos y procesos administrativos, estableciendo la vinculación entre ambos y sus efectos. A continuación se estudian algunas particularidades de los procesos especiales y generales dispuestos en el ordenamiento jurídico para el juzgamiento de estas materias, analizando las relaciones jurídicas entre ellos.

\section{Palabras Clave}

Justicia Administrativa - Procedimiento Administrativo - Proceso Administrativo - Tutela Judicial.
\end{abstract}

\section{Abstract}

This work analyzes the processes through which the administrative justice develops in the Chilean Law. For these purposes, we begin by making a difference between administrative procedures and processes by establishing their connections and their effects. Then, some traits of the especial and general processes ordered in the legal system for the judgment of these matters are studied, by analyzing the legal relationships between them.

\section{KeYWORDS}

Administrative Justice - Administrative Procedure - Administrative Process - Judicial Protection.

[RECIBIDo el 8 de marzo y APRobado el 18 de mayo de 2011].

* Este trabajo forma parte del proyecto FONDECYT No 1100313: "El sistema de justicia administrativa en el derecho chileno: ¿control de legalidad al acto administrativo o tutela de derechos y/o intereses legítimos?", del que el autor es investigador principal.

${ }^{* *}$ Licenciado en Ciencias Jurídicas y Sociales, Universidad de Chile; Doctor en Derecho, Universidad Carlos III de Madrid. Profesor de Derecho administrativo de la Universidad de Valparaíso. Dirección postal: Avenida Errázuriz 2120, Valparaíso, Chile. Correo electrónico: juancarlos.ferrada@uv.cl 


\section{INTRODUCCIÓN}

Los actos administrativos son actos jurídicos emanados de un órgano de la Administración del Estado que poseen ciertas cualidades y características que los hacen, en cierto sentido, excepcional dentro del ordenamiento jurídico. Esa excepcionalidad les permite, entre otras cosas, gozar de una presunción de legalidad o validez desde su inicio, lo que lleva aparejado su ejecutividad, ejecutoriedad y aún su ejecución forzosa, en ciertos casos (artículo 3 y 51 de la Ley $\mathrm{N}^{\circ}$ 19.880: sobre Bases de los Procedimientos Administrativos).

Lo anterior supone un privilegio para la Administración del Estado, que es consecuencia de la importante finalidad que tiene a su cargo, la protección de los intereses públicos ${ }^{1}$, pero que desde la perspectiva del administrado impone una carga procedimental adicional para su resistencia: la impugnación del acto administrativo. En efecto, el administrado si desea resistirse u oponerse al cumplimiento del acto administrativo o discutir su validez, debe impugnarlo por los mecanismos establecidos en el ordenamiento jurídico, ya que de no hacerlo la Administración contará con un título habilitante para poner en ejecución el mismo, por la vías administrativas o judiciales dispuestas por la ley. A esto es lo que la doctrina comparada denomina "autotutela declarativa", y que supone un desplazamiento de "la carga de accionar a la otra parte, gravada con la necesidad de poner en movimiento una acción impugnatoria para destruir la eficacia inmediata que, por su propia fuerza, alcanzan las decisiones administrativas"2.

Ahora bien, para que los particulares puedan satisfacer esta carga y proteger sus derechos o intereses, el ordenamiento jurídico debe proveer de mecanismos eficaces para impugnar estos actos, discutiendo la validez de los mismos y paralizando, en su caso, su ejecutividad y ejecutoriedad. Precisamente, esta última circunstancia es uno de los elementos que conspira en nuestro Derecho para una adecuada defensa de los derechos o intereses privados, ya que, por un lado, los procedimientos dispuestos para su impugnación no están claramente establecidos y regulados; y, por otro, el efecto suspensivo o cautelar propio de estos procedimientos no está bien afianzado en nuestro Derecho.

En este contexto, este trabajo pretende realizar un análisis general de los principales mecanismos dispuestos en el ordenamiento jurídico chileno para impugnar los actos administrativos, tanto en el ámbito de la propia

${ }^{1}$ Ferrada Bórquez, Juan Carlos, Las potestades y privilegios de la Administración Pública en el régimen administrativo chileno, en Revista de Derecho de la Universidad Austral de Chile, 20 (2007) 2, pp. 75-76

${ }^{2}$ García de Enterría, Eduardo - Fernández, Tomás Ramón, Curso de Derecho administrativo (7ª edición, reimpresión, Madrid, Civitas, 1996), I, pp. 493. 
Administración del Estado, como de los tribunales de justicia, prestando una especial atención a estos últimos. Así, en el primer apartado se hará una referencia general a los procedimientos y procesos de impugnación de estos actos y los efectos que produce dicha impugnación; en el segundo se analizarán más concretamente los procesos especiales y generales en materia de justicia administrativa, sin estudiar en detalle los mismos, sino sólo haciendo un análisis general de los mismos, con el objeto de establecer algunas relaciones jurídicas relevantes entre éstos; finalmente, se formularán algunas conclusiones que se consideran importantes en esta materia.

\section{LOS PROCEDIMIENTOS Y PROCESOS DE IMPUGNACIÓN} DE LOS ACTOS ADMINISTRATIVOS

\section{Las vias administrativas y judiciales de impugnación.}

a) La distinción entre procedimientos y procesos administrativos. En el ordenamiento jurídico chileno, como también ocurre en el Derecho comparado, existen vías administrativas y judiciales de impugnación de los actos administrativos. Las primeras, que las leyes chilenas denomina "recursos", son los que la doctrina comparada identifica como "procedimientos administrativos" de impugnación y corresponden, en el Derecho chileno, a los denominados recursos administrativos (artículos 2 y 10 de la Ley orgánica constitucional de bases generales de la administración del Estado). Estos recursos son, en nuestro Derecho, los recursos ordinarios de reposición y jerárquico, ambos mecanismos establecidos para impugnar el acto ante la misma autoridad que los dictó o ante el superior jerárquico, a través de los que se puede revisar no solo la legalidad de la actuación administrativa, sino la oportunidad o conveniencia de la misma (artículo $1^{\circ}$ y 11 de la Ley orgánica constitucional de bases generales de la administración del Estado y artículo 59 de la Ley $\mathrm{N}^{\circ}$ 19.880: sobre Bases de los procedimientos administrativos). Junto a ellos se encuentra el recurso extraordinario de revisión, procedimiento administrativo excepcional establecido en el ordenamiento jurídico que permite la revisión de la decisión administrativa, pero sólo por las causales expresamente establecidas en la ley, constituyendo una excepción calificada a la firmeza de los actos administrativos (artículo 60 de la Ley $\mathrm{N}^{\circ}$ 19.880: sobre Bases de los procedimientos administrativos)

Por otro lado, se encuentran las denominadas vías judiciales de impugnación, que las leyes chilenas denominan "acciones" o "acciones jurisdiccionales", y corresponden a los procesos administrativos propiamente tales (artículo 2 y 10 de la Ley orgánica constitucional de bases generales de la Administración del Estado y artículos 15 y 54 de la Ley de bases de los procedimientos administrativos), y que son a través de los cuales se pone en conocimiento de 
un tribunal la controversia jurídica, solicitándole la revisión de la actuación administrativa o la tutela de un derecho o interés, en conformidad al ordenamiento jurídico. En estos casos la potestad de revisión del tribunal es más acotada, ya que sólo se somete a la decisión del tribunal los aspectos jurídicos de la decisión -aspectos de forma y fondo-, estándole vedado al tribunal revisar los aspectos de mérito o conveniencia, ya que ello entra dentro de la órbita de actuación de la propia Administración del Estado. Lo anterior no impide, evidentemente, que el tribunal pueda revisar los presupuesto de hecho que establece la norma para el ejercicio de la potestad, ya que éstos forman parte del control de juridicidad de le ejercicio de la potestad por parte del órgano de la Administración del Estado.

De lo hasta aquí expuesto, es claro que ambas vías, procedimientos y procesos administrativos, permiten la revisión de la legalidad de la actuación administrativa y la tutela de derechos o intereses de los administrados, pudiendo también la autoridad o el tribunal, complementariamente, declarar la invalidación o la nulidad del acto y aún, en ciertos casos, dictar un acto administrativo que sustituya o reemplace la decisión dejada sin efecto. Así, la diferencia fundamental entre ambos estriba en que los primeros - los procedimientos administrativos- se ventilan ante la propia autoridad administrativa y en ellos, como ya se señaló, la autoridad administrativa no sólo puede revisar la legalidad de la actuación administrativa, sino también la oportunidad y el mérito de ésta. En cambio en los segundos, los procesos administrativos, se desarrollan ante un tribunal de justicia, y en éstos sólo cabe la revisión de la legalidad del acto u omisión de la Administración, ya que están sujetos estrictamente, como se sabe, al principio de legalidad ${ }^{3}$.

b) La relación jurídica entre procedimientos y procesos administrativos impugnatorios. Una cuestión bastante compleja es determinar la relación jurídica que existe entre estos procedimientos administrativos y los procesos administrativos, es decir, identificar la forma como se relacionan ambas vías de impugnación, y que determinan el uso de las mismas por lo administrados: En otras palabras, se trata de determinar si en el ordenamiento

${ }^{3}$ La diferencia entre procedimientos y procesos administrativos es una cuestión bastante más clara en el derecho comparado. Sin embargo en el derecho chileno es una distinción poco clara, cuya confusión probablemente justifica algunos de los problemas conceptuales en el desarrollo de la justicia administrativa. Sobre las características propias del proceso administrativo, distinguiéndolo de los procedimientos administrativos internos, ver, por todos, González Pérez, Jesús, Derecho procesal administrativo (Madrid, Civitas, 2000), pp. 67-72 y, desde una perspectiva más teórica, SCHмIDTAssmann, Eberhard, La teoría general del Derecho administrativo como sistema (Madrid, INAP - Marcial Pons, 2003), pp. 381-382. 
jurídico se establece una orden de prelación, exclusión, complementariedad o sustitución entre ambas vías impugnatorias.

En el Derecho chileno, el artículo 54 de la Ley $N^{\circ}$ 19.880: sobre Bases de los procedimientos administrativos establece, aparentemente, la regla general en esta materia, otorgando a los particulares un derecho de opción para utilizar a su arbitrio los procedimientos o los procesos administrativos de impugnación, según estimen conveniente. En otras palabras, el ordenamiento jurídico nacional no exige un orden de prelación entre los procedimientos y procesos administrativos de impugnación, ni aún el paso previo por los primeros para llegar a los segundos, sino que otorga a los administrados el derecho de elegir la vía de impugnación específica en cada caso.

Esta es una regla de gran importancia en el Derecho administrativo, ya que con ello establece que no es necesario que el particular agote la vía administrativa para impugnar judicialmente el acto, sino que es el propio particular el que debe optar por la vía administrativa o judicial, según su estrategia de defensa. No obstante, si el particular opta por la vía administrativa de impugnación -recurso de reposición y/o jerárquico-, el legislador dispone, en el mismo artículo 54 de la Ley $\mathrm{N}^{\circ} 19.880$, que ello le impone a aquel la obligación de agotar la vía administrativa de reclamo, generándose un impedimento para el ejercicio de las acciones judiciales ${ }^{4}$.

Por el contrario, la misma disposición legal antes citada señala, si el particular opta por la vía judicial de impugnación, sin entablar previamente los recursos administrativos disponibles, la Administración queda totalmente impedida de conocer de una impugnación administrativa del mismo acto, ya que la materia ya se encuentra sometida al conocimiento de los tribunales de justicia. Así en esta caso ha operado una especie de preclusión, cuyo fundamento es la judicialización del conflicto jurídico, lo que evidentemente hace inviable un pronunciamiento de la Administración, ya porque quedaría sujeto a la decisión judicial, ya porque de emitirlo después de la resolución judicial, podría llevar a configurar un simple desacato de lo resuelto por el tribunal.

Como se puede observar, el diseño legislativo es reconocer a los particulares un derecho de opción en esta materia, que le permite un agotamiento de la vía administrativa antes de llevar el asunto ante los tribunales de justicia,

${ }^{4}$ Bermúdez, señala en este sentido que, en este caso, esta impugnación del acto a través de los recursos administrativos impedirá precisamente la impugnación judicial, lo que la propia Administración podría hacer valer en nuestro derecho a través de la excepción dilatoria amplia establecida en el artículo $303 \mathrm{~N}^{\circ} 6 \mathrm{CPC}$. BERMúdez Soto, Jorge, Derecho administrativo general (Santiago de Chile, Abeledo Perrot - Legal Publishing, 2010), p. 137. 
pero sin llegar a configurar un impedimento a los particulares para el acceso directo a aquellos.

Esta solución planteada en el artículo 54 de la Ley $\mathrm{N}^{\circ} 19.880$ sobre Bases de los Procedimientos Administrativos parece bastante consistente con el reconocimiento que se hace en el constitucionalismo moderno del derecho fundamental a la acción o tutela judicial, el que impediría el establecimiento de obstáculos o condiciones que hicieran imposible o extremadamente gravoso el acceso a los tribunales de justicia. Así, la exigencia legal de un agotamiento previo de la vía administrativa, como presupuesto para el ejercicio de las vías judiciales de impugnación -como se exige, por regla general, en el Derecho administrativo español-, pondría aparentemente en entredicho este derecho fundamental, ya que impondría una carga al particular que denegaría o al menos haría más dificultoso el ejercicio del derecho fundamental a la acción o tutela judicial. De ahí que la doctrina comparada critique esta exigencia de la interposición de los recursos administrativos, como presupuesto para el ejercicio de las acciones judiciales, más aún considerando la extensión temporal de la tramitación de los primeros y su inoperancia como mecanismo suspensivo de la decisión administrativas.

En este contexto, la opción adoptada por el legislador chileno en el artículo 54 de la Ley $N^{\circ}$ 19.880: sobre Bases de los procedimientos administrativos sería más coherente con el derecho fundamental a la acción o de tutela judicial, el que por lo demás encuentra expreso reconocimiento constitucional en el artículo $19 \mathrm{~N}^{\circ} 3 \mathrm{CPol}$.

Sin embargo, si vamos más allá de la disposición legal antes citada y analizamos el conjunto del ordenamiento jurídico chileno, podemos fácilmente observar que esta regla se invierte en muchas ocasiones, estableciéndose perentoriamente la exigencia del agotamiento de la vía administrativa antes de la impugnación del mismo acto ante los tribunales de justicia. Así, por ejemplo, en materia del reclamo de ilegalidad municipal (artículo 141 de la Ley orgánica constitucional de municipalidades), el reclamo de ilegalidad regional (artículo 108 de la Ley orgánica constitucional de gobiernos regionales), el reclamo contra el acto que imponga sanciones administrativas por la Superintendencia de Electricidad y Combustibles (artículo 18 ss. de la Ley $\mathrm{N}^{\circ} 18.410$ que crea la Superintendencia de Electricidad y Combustibles) o la impugnación de la decisión administrativa que establece el secreto o reserva de documentos (artículos 24 y 28 de la Ley N 20.285 : sobre Acceso a la información pública), por nombrar sólo algunos casos, el legislador ha

${ }^{5}$ En términos similares, criticando la formulación legal española, véase, por todos: García de Enterría, Eduardo - Fernández, Tomás-Ramón, Curso de Derecho administrativo ( $4^{\circ}$ edición, reimpresión, Madrid, Civitas, 1997), II, pp. 508 ss. 
dispuesto precisamente que la vía judicial ante el tribunal correspondiente -Corte de Apelaciones, en la mayoría de los casos- sólo es admisible una vez resuelta la impugnación administrativa por el jefe superior del Servicio o el órgano competente, fecha desde la cual se cuenta precisamente el plazo para impugnar judicialmente el acto.

De este modo, en estos casos citados, así como en otros establecidos por leyes especiales, el legislador chileno ha dispuesto precisamente la regla contraria a la señalada en el artículo 54 de la Ley $\mathrm{N}^{\circ} 19.880$ sobre Bases de los procedimientos administrativos, es decir, ha señalado que la vía judicial de impugnación sólo es admisible una vez resuelta administrativamente la impugnación, o bien resuelta fictamente ésta, como aplicación de la regla del silencio negativo, en ciertos casos. Así la regla del derecho de opción para impugnar el acto administrativo y el reconocimiento de la vía judicial directa, en su caso, pierde eficacia en el ordenamiento chileno, estableciendo en muchos casos la regla exactamente contraria del agotamiento de la vía administrativa previa como presupuesto de la impugnación judicial.

Ahora bien, lo anterior no supondría, en principio, un problema jurídico mayor, desde la perspectiva de la coherencia del ordenamiento legal, ya que el artículo 54 de la Ley $\mathrm{N}^{\circ} 19.880$ sobre Bases de los procedimientos administrativos, es una norma supletoria, según lo dispone el artículo 1 de la misma ley, por lo que frente a reglas especiales que disponen lo contrario, se aplica la regla especial dispuesta para ese procedimiento especial impugnatorio. Sin embargo, dicha disparidad normativa da cuenta de la diversidad de regímenes jurídicos dispuestos en nuestro ordenamiento en esta como en otras materias, además de dejar en evidencia los limitados efectos que tiene la Ley de bases de los procedimientos administrativos como norma general uniformadora de los procedimientos administrativos en nuestro medio ${ }^{6}$.

Cuestión distinta, y algo más compleja, es determinar la conformidad de estas reglas especiales con el texto constitucional chileno, a partir del ya señalado reconocimiento del derecho fundamental a la acción o tutela judicial en aquel (artículo $19 \mathrm{~N}^{\circ} 3 \mathrm{CPol}$.). Así, si se fuera coherente y consistente con el fundamento de la opción tomada por la Ley $\mathrm{N}^{\circ}$ 19.880: sobre Bases de

${ }^{6} \mathrm{Ya}$ es conocida la polémica suscitada en nuestro derecho por la aplicación de la Ley N ${ }^{\circ}$ 19880: sobre Bases de los Procedimientos Administrativos, que transita desde la consideración de una simple norma supletoria, hasta la configuración de una verdadera norma de bases, configurativa de los procedimientos administrativos especiales y, por lo mismo, indisponibles para ellos. Sobre esto véase, por todos: Vergara Blanco, Alejandro, Eficacia derogatoria y supletoria de la Ley de Bases de los Procedimientos Administrativos, y CORDERO VEGA, Luis, La supletoriedad en la Ley de bases de procedimiento administrativo, ambos en Acto y procedimiento administrativo (Valparaíso, Ediciones Universitarias de Valparaíso, s. d), pp. 31-47 y 49-69, respectivamente. 
losprocedimientos administrativos, necesariamente se tendría que cuestionar o al menos poner en duda la constitucionalidad de dichas regulaciones, ya que en la práctica imponen un requisito o condición previa al acceso a la vía judicial de reclamo dispuesta para esos casos específicos ${ }^{7}$. Así, el particular no podría interponer directamente el reclamo de ilegalidad municipal o regional directamente ante la Corte de Apelaciones respectiva, ya que no cumpliría con un requisito o condición de admisibilidad del reclamo, además de generarse problemas prácticos relacionados con el cómputo del plazo para su interposición ${ }^{8}$.

No obstante, esta interpretación estricta de la norma constitucional en comento, que impediría la exigencia de la vía administrativa previa, antes de la impugnación judicial del acto, no es absolutamente compartido ni por la doctrina, ni la jurisprudencia nacional y comparada. En efecto, si analizamos los procesos judiciales de impugnación de ciertos actos administrativos en el Derecho chileno, se puede observar que el Tribunal Constitucional ha declarado implícitamente la constitucionalidad de vías administrativas previas, como requisito o condición para la impugnación judicial, sin que ello motive reparo u objeción de algún tipo ${ }^{9}$. Aún más, el diseño institucional de estos procesos ha supuesto, en reiteradas oportunidades, el establecimiento de una vía administrativa de reclamo como paso previo a la impugnación

${ }^{7}$ Esta es precisamente la interpretación que hace Aróstica Maldonado, Iván, Los contenciosos administrativos especiales en la legislación chilena, en Ius Publicum, 20 (2008), p. 97, para el Derecho chileno, siguiendo precisamente a González Pérez, cuando señala que exigencias de este tipo en nuestro ordenamiento son "flagrantemente inconstitucionales", ya que, en sus palabras, "suspenden (prohíben transitoriamente) el ejercicio del derecho a la acción reconocido por la Constitución (artículo 19 No 3), al impedirle al afectado acudir sin más trámite ante los tribunales en defensa de sus derechos"..

${ }^{8}$ Recuérdese que el plazo para la interposición del reclamo de ilegalidad municipal es de 15 días hábiles, los que son precisamente contabilizados desde el rechazo expreso o presunto del reclamo (artículo 141 letra d) de la Ley orgánica constitucional de municipalidades). Si un particular quisiera entablar directamente el reclamo judicial, sin pasar previamente por la vía administrativa dispuesta en la ley, la única manera de contabilizar los plazos sería desde el acto administrativo original, lo que supondría un menor plazo que el dispuesto para la impugnación administrativa (30 días).

${ }^{9}$ Precisamente 3 de los ejemplos antes señalados, en materia municipal (artículo 141 de la Ley orgánica constitucional de municipalidades), regional (artículo 108 de la Ley orgánica constitucional de gobiernos regionales) y acceso a la información pública (artículo 24 y 28 de la Ley $N^{\circ}$ 20.285: sobre Acceso a la información pública), las leyes correspondientes pasaron por el control preventivo del Tribunal Constitucional, en ninguno de ellos éste planteó objeción alguna al modelo del agotamiento de la vía administrativa previa, antes de la impugnación del mismo acto ante los tribunales de justicia. 
judicial, otorgándole incluso al primero el carácter de instancia judicial para todos los efectos legales ${ }^{10}$.

Ahora bien, en la doctrina y jurisprudencia comparada tampoco parece existir una interpretación uniforme de esta materia, ya que algunos afirman la plena constitucionalidad de esta exigencia del agotamiento de la vía administrativa, siempre que éste tenga una fundamentación y construcción razonable, como paso previo a la impugnación judicial del acto. Así, en el Derecho español, por ejemplo, Sánchez Morón, citando la sentencia del Tribunal Constitucional 60/1989, señala que "en sí misma, la vía administrativa previa de recurso es admisible en nuestro Derecho, siempre que obedezca a 'razonables finalidades de protección de bienes e intereses constitucionalmente protegidos' y que no supongan un obstáculo carente de 'razonabilidad y proporcionalidad' respecto de los fines que lícitamente puede perseguir el legislador" ${ }^{11}$. En este sentido, la exigencia de la vía administrativa previa no constituiría una regla inconciliable con el derecho a la acción o la tutela judicial, sino sólo cuando aquella es desproporcionada o impone unos obstáculos insalvables o no razonables con el derecho o interés disputado.

Además -volviendo a nuestro Derecho-, esta exigencia de cumplir con instancias administrativas previas, antes de la interposición de la acción judicial, no sólo opera en el ámbito contencioso administrativo anulatorio y en relación con recursos administrativos impugnatorios. También se contempla esta fórmula como requisito o condición para el ejercicio de otras acciones judiciales, aunque en este caso como mediación obligatoria. Así, por ejemplo, en los casos de responsabilidad del Estado por los daños provenientes de la actividad sanitaria (Ley $\left.\mathrm{N}^{\circ} 19.966\right)$ o, en un ámbito más del Derecho privado, en las causas de alimentos, cuidado personal de los hijos y regulación de la relación directa y regular (Ley $\mathrm{N}^{\circ} 19.968$, modificada por la Ley $\mathrm{N}^{\circ}$ 20.286: que Crea los tribunales de familia), el ordenamiento prevé la mediación obligatoria, la que no llevarse a cabo impide el acceso al tribunal competente.

Como se puede observar, la interposición de los recursos administrativos

${ }^{10}$ Véase, entre otros, el procedimiento dispuesto para la impugnación del acto emanado del Consejo Nacional de Televisión (artículo 27 de la Ley $\mathrm{N}^{\circ} 18.838$ ), que es impugnable ante la Corte de Apelaciones de Santiago; o el de la impugnación del acto sancionatorio dispuesto por el Ministro de Transporte y Telecomunicaciones ante la misma Corte (artículo 36 A de la Ley general de telecomunicaciones).

${ }^{11}$ Sánchez Morón, Miguel, Recursos administrativos, en Leguina Villa, Jesús - Sánchez Morón, Miguel (directores), La nueva Ley de régimen jurídico de las administraciones públicas y del procedimiento administrativo común (Madrid, Tecnos, 1993), p. 322. En términos similares, destacando las ventajas de este sistema de agotamiento de la vía administrativa, Parejo Alfonso, Luciano, Derecho administrativo (Barcelona, Ariel, 2003), p. 1.089. 
impugnatorios de un acto administrativo no constituye una regla general en nuestro Derecho administrativo para el acceso a la vía judicial, sino al contrario se establece un derecho de opción a los particulares. Sin embargo, los procesos especiales pueden contener esta regla, la que, en principio, no sería incompatible con la regla dispuesta en el artículo 54 de la Ley $\mathrm{N}^{\circ}$ 19.880: sobre Bases de los procedimientos administrativos, ni con el derecho fundamental a la acción o tutela judicial dispuesto en el artículo $19 \mathrm{~N}^{\circ} 3 \mathrm{CPol}$.

\section{Los efectos suspensivos de la impugnación administrativa del acto, respecto} de las acciones judiciales.

a) El régimen suspensivo general de los recursos administrativos. El diseño del derecho de opción de los particulares para impugnar administrativa o judicialmente el acto requiere, para ser eficaz, que el particular, en el caso que opte por la vía administrativa de impugnación, pueda posteriormente impugnar judicialmente el acto, en el evento que la autoridad administrativa rechace el recurso administrativo. Ello requiere que el plazo legal dispuesto para la utilización de las acciones judiciales previstas se suspenda o interrumpa, ya que de otro modo se extinguirían por el mero transcurso del tiempo o se disminuiría significativamente el plazo previsto para ello.

En este sentido, la Ley $\mathrm{N}^{\circ}$ 19.880: sobre Bases de los procedimientos administrativos establece precisamente la interrupción del plazo para el ejercicio de las acciones judiciales, desde el momento en que se produce la impugnación administrativa de los actos u omisiones específicos. Así, el artículo 54 de la citada ley señala que "planteada la reclamación se interrumpirá el plazo para ejercer la acción jurisdiccional", quedando garantizado al particular el uso de esta última, en el caso de que se desestime por la autoridad la primera.

Como bien apunta Bermúdez ${ }^{12}$, la ley con propiedad habla en este caso de "interrupción" y no de "suspensión", ya que con ello permite al particular utilizar el plazo íntegro dispuesto por el legislador para impugnar judicialmente el acto y no la fracción restante dejado por el ejercicio del recurso administrativo. De este modo, el plazo para impugnar judicialmente el acto se volverá a contar desde la fecha en que se notifique el acto que resuelve la impugnación administrativa o, en su caso, desde que la reclamación se entienda desestimada por el mero transcurso del plazo, operando la regla del silencio negativo que establece el artículo 65 de la misma Ley $\mathrm{N}^{\circ} 19.880$.

Este es precisamente el criterio utilizado por nuestro máximo tribunal, ya que ha considerado interrumpido los plazos legales para la interposición de las acciones judiciales, si el particular ha deducido los recursos administra-

\footnotetext{
${ }^{12}$ Bermúdez Soto, Jorge, cit. (n. 4), p. 138.
} 
tivos correspondientes. Este criterio se aplica, según la Corte Suprema, aún tratándose de procedimientos especiales de impugnación, ya que también en estos casos se sigue la regla del artículo 54 de la Ley $\mathrm{N}^{\circ}$ 19.880: sobre Bases de los procedimientos administrativos, como regla general del Derecho administrativo ${ }^{13}$.

La regla anterior, en conclusión, permite a los particulares utilizar todos los mecanismos legales de impugnación de los actos administrativos, ya que puede utilizar primeramente las vías administrativas de reclamo, y ante la respuesta negativa de la autoridad, ejercer las acciones judiciales dispuestas para ello. En todo caso, como ya se ha señalado, interpuesto el recurso administrativo impugnatorio, el particular debe esperar la resolución de la autoridad administrativa, transformándose esta respuesta en un requisito de admisibilidad de la acción judicial que se interponga con posterioridad.

Evidentemente, como ha quedado establecido, esta habilitación para el ejercicio de recursos administrativos impugnatorios no impide el ejercicio directo de las vías judiciales de reclamo, sin pasar en forma previa por las administrativas, pero existirá un evidente incentivo para usar ambas vías, ya que la utilización de estas últimas no inhibe el ejercicio posterior de aquellas, lo que aumenta las posibilidades de obtener una resolución favorable del asunto controvertido. Lo anterior es sin prejuicio de las limitaciones que poseen las vías administrativas de reclamo en el Derecho administrativo, ya en cuanto a la imparcialidad del órgano resolutor, ya en relación con la extensión temporal de los plazos de resolución de la controversia con la Administración, lo que puede generar en la práctica, en ciertos casos, el incentivo al uso de las vías judiciales directamente ${ }^{14}$.

Ahora bien, esta regla suspensiva no tiene aplicación en los casos en que el ordenamiento jurídico establece la impugnación administrativa como una condición o requisito para el ejercicio de las acciones judiciales, ya que en tales casos la propia ley es la que señala un plazo para la impugnación judicial, el que se cuenta precisamente desde la resolución administrativa que rechaza total o parcialmente el recurso administrativo impugnatorio. Así, en el caso del procedimiento impugnatorio previsto contra la resolución administrativa que establece el carácter reservado o secreto de un documento, la propia ley señala que el reclamante dispone de quince días corridos, contados precisamente desde la "notificación de la resolución reclamada" (artículo 28 de la Ley $\mathrm{N}^{\circ} 20.285$ sobre acceso a la información pública), lo que hace inútil

${ }^{13}$ Sentencia de la Corte Suprema, "María Correa y Cía. Ltda. con Secretario Regional Ministerial de Salud de la Región Metropolitana”, rol N 7412/2008, de 30 de junio de 2010.

${ }^{14}$ Véase: García de Enterría, Eduardo - Fernández, Tomás-Ramón, Curso, cit. (n. 5), II, p. 509. 
el establecimiento de una suspensión o interrupción del plazo mientras se impugna administrativamente el acto.

b) La situación especial del recurso de protección. Esta regla de interrupción de los plazos legales para la interposición de las acciones judiciales, pendiente los recursos administrativos impugnatorios del mismo acto, presenta una excepción muy calificada, por vía jurisprudencial, en el recurso de protección, proceso judicial de tutela de derechos fundamentales utilizado frecuentemente como contencioso administrativo en nuestro Derecho. En efecto, la jurisprudencia constante de la Corte Suprema ha señalado en esta materia -con algunas excepciones ya de larga data ${ }^{15}$-, que la interposición de los recursos administrativos impugnatorios no suspende ni interrumpe el plazo de treinta días corridos, previsto en el Auto acordado para la interposición del recurso de protección ${ }^{16}$. Este criterio ha sido reiterado por la misma Corte recientemente, señalando que el plazo dispuesto en el ordenamiento "se cuenta desde la fecha en que el interesado conoce del agravio, real o inminente, a sus derechos esenciales", por lo que al impugnar la parte el acto en la vía administrativa, el plazo dispuesto para la interposición del recurso de protección sigue corriendo desde la fecha de emisión original del acto ${ }^{17}$.

Ahora bien, este pronunciamiento jurisprudencial implica que la interposición de un recurso administrativo de reposición con jerárquico en subsidio, no genera el efecto de interrupción general del plazo para la interposición de las acciones judiciales en el caso del recurso de protección, transcurriendo éste desde la notificación del acto administrativo original. Así, interpuesto el recurso administrativo, el particular deberá paralelamente $-\mathrm{o}$ al menos antes de que transcurran treinta días corridos-interponer el recurso de protección ante la Corte de Apelaciones respectiva, aún sin esperar el resultado de aquel, ya que sino será declarado extemporáneo este último, si se presenta con posterioridad a la resolución administrativa dispuesta por la autoridad.

Este curioso criterio del máximo tribunal, que implica, en la práctica, un incentivo a la presentación paralela de recursos administrativos y recurso de

\footnotetext{
${ }^{15}$ Sentencia de la Corte Suprema, “Aguilera Jara con Director Regional del Servicio de Impuestos Internos”, rol No 821/2005, de 8 de marzo de 2005.

${ }^{16}$ Sentencia de la Corte Suprema, "Thunderbird IEG con Superintendencia de Casinos", rol No 1717/2006, de 31 de mayo de 2006. En el mismo sentido, posteriormente, sentencias de la Corte de Apelaciones de Concepción, confirmada por la Corte Suprema, “Acuña Flores con Contralor Regional del Bío-Bío”, rol № 75-2007, de 5 de junio de 2007; y sentencia de la Corte Suprema, "Sociedad Educacional Pablo Neruda de Talca Ltda. con Secretaría Regional Ministerial de Educación de la Región del Maule", rol N $7618 / 2009$, de 29 de diciembre de 2009.

${ }^{17}$ Sentencia de la Corte Suprema, "Salazar Godoy con Comisión Médica Central de la Superintendencia de Pensiones”, rol N³324/2010, de 7 de junio de 2010.
} 
protección, pareciera estar justificado -y así lo señala el máximo tribunal en sus fallos- en la urgencia y celeridad que exige este proceso de tutela urgente de derechos fundamentales y la propia naturaleza excepcional de éste, el que no puede ser coartado, limitado, suspendido o interrumpido por disposición legal alguna. Ello además estaría respaldado, en opinión de la Corte, en lo dispuesto en el propio artículo $20 \mathrm{CPol}$., al disponer que este proceso de amparo opera "sin perjuicio de los demás derechos que pueda hacer valer ante la autoridad o los tribunales correspondientes", lo que excluiría la posibilidad de suspender o impedir temporalmente uso, como lo establece el artículo 54 de la Ley $\mathrm{N}^{\circ} 19.880$, como efecto directo de la interposición de los recursos administrativos impugnatorios.

No obstante, esta interpretación -como ya lo he sostenido anteriormente $^{18}$ - no parece muy consistente con los objetivos perseguidos por el legislador al disponer la regla del artículo 54 ya citado, con una efectiva protección de los derechos de los particulares y, aún menos, con la utilización eficiente del sistema judicial. En efecto, precisamente el objetivo perseguido por el legislador no era impedir el acceso de los particulares a los tribunales de justicia, sino al contrario allanarle el camino, permitiendo la utilización de esta vía de impugnación de los actos administrativos y de protección de sus derechos en el momento que el estime conveniente, pero sin imposibilitar alguno por la sola reclamación administrativa del acto. La lectura dada por el tribunal, como impedimento del uso del recurso de protección por la interposición de los recursos administrativos, es una lectura parcial y limitada del precepto legal, que sólo apunta a la inmediatez e importancia del proceso de tutela de derechos fundamentales, pero no reflexiona sobre la coherencia del sistema de control de la actividad administrativa.

Además, con esta interpretación jurisprudencial el particular queda prácticamente constreñido -a propósito del recurso de protección solamente-, como ya se ha dicho, a una utilización simultánea o alternativa de ambas vías de impugnación (administrativa y judicial), lo que hace ineficaz la vía administrativa y recarga innecesariamente la vía judicial general. En efecto, el particular que crea conveniente utilizar el recurso de protección como un mecanismo de impugnación del acto administrativo, por considerar que hay también un derecho fundamental vulnerado, va a tener que interponer necesariamente éste en desmedro del recurso administrativo o utilizando éste de una forma testimonial, ya que la Administración carecerá de incentivo e interés por resolverlo, sabiendo que se encuentra pendiente

${ }^{18}$ Véase, en este sentido, mi comentario de jurisprudencia Sentencia sobre interpretación del Artículo 54 LBP A que establece la interrupción de los plazos judiciales mientras se resuelven recursos administrativos interpuestos previamente (Corte Suprema), en Revista de Derecho de la Universidad Austral de Chile, 19 (2006) 2, pp. 257-264. 
un recurso judicial. Esto lleva a la judicialización inmediata del conflicto administrativo y entraña una nueva deformación del recurso de protección en el sistema jurídico.

\section{LOS PROCESOS ADMINISTRATIVOS ESPECIALES Y GENERALES DE IMPUGNACIÓN}

\section{La diversidad de los procesos administrativos especiales y generales.}

Como ya se apuntó en la introducción de este trabajo, existe en nuestro Derecho una gran diversidad de procesos administrativos dispuestos para impugnar la actividad de los órganos que integran la Administración del Estado. Así, se puede apreciar una amplia variedad de procesos especiales dispuestos por el legislador para conocer de estas controversias, los que tienen características y elementos especiales, atendida la materia específica que regulan. Así el legislador chileno ha ido configurando procesos contenciosos administrativos particulares para controlar la actividad administrativa en cada sector o actividad que considera relevantes, diseñando éstos con ciertas particularidades atendido los derechos involucrados, la gravedad de la actividad desplegada por la Administración y el órgano específico que emite el acto.

En este contexto, es evidente que la opción seguida por el legislador chileno ha sido establecer no uno, sino una amplia variedad de procesos especiales para impugnar los distintos actos u omisiones de los órganos administrativos, especialmente en aquellas materias que considera relevantes para la protección de los derechos de las personas o cautelar los intereses públicos comprometidos. Ello ha tenido un particular desarrollo -como veremos a continuación - en ámbitos de actividad administrativa con efectos en sectores económicos relevantes, estableciéndose en la práctica una justicia especializada y privilegiada en ciertos ámbitos específicos - una especie de justicia administrativa "de alfombra roja"-, cuya calidad, eficacia y celeridad contrasta con los problemas de la justicia civil en general.

Ahora bien, sin perjuicio de ello, en el Derecho administrativo chileno existen también, como ya veremos, procesos generales de control de la actividad administrativa, como son los denominados "acción de nulidad de Derecho público" y el "recurso de protección", los que presentan ciertas particularidades inexplicables desde la perspectiva del Derecho comparado. Ambos procesos, como se verá, son de aplicación general y común, y pueden ser utilizados por los particulares para impugnar cualquier acto u omisión administrativa, siempre que se encuadre en alguna de las causales o presupuestos de admisión que establece el propio ordenamiento. Precisamente las dificultades para encuadrar estas impugnaciones en las causales legales 
de procedencia será uno de los problemas que presentará mayores inconvenientes y limitaciones como procesos ordinarios de control contencioso administrativo.

\section{La aparición y consolidación de los contenciosos administrativos especiales} en el Derecho administrativo chileno.

Como ya se señaló, en nuestro Derecho existe un conjunto de procesos administrativos especiales para impugnar ciertos actos de la Administración del Estado, controlando la legalidad de éstos o tutelando los derechos o intereses de los particulares afectados. El profesor Carmona Santander, en un estudio publicado el año $2005^{19}$, cifraba en 120 los contenciosos administrativos especiales al año 2003, cifra que ha seguido incrementándose posteriormente, alcanzando una cifra cercana a los 140 actualmente, dando lugar a una verdadera "inflación contenciosa" ${ }^{20}$ en nuestro Derecho. Es cierto que muchos de ellos ya venían desde hace treinta años o más, especialmente con la construcción del modelo neoliberal de mercado y la configuración de un Estado regulador que requería de procedimientos de control de la actividad estatal frente a estos nuevos operadores privados, pero ello parece acentuarse en las dos últimas décadas, abandonando lamentablemente la opción de generar un contencioso administrativo general, como se había previsto originalmente en la Constitución de 1980.

En este contexto, como ya se ha venido señalando, el legislador chileno ha establecido procesos administrativos especiales para conocer las impugnaciones de actos emanados de órganos especializados de la Administración del Estado en ámbitos tan diversos como las telecomunicaciones (artículo 39 de la Ley general de telecomunicaciones), la televisión (artículo 34 de la Ley $\mathrm{N}^{\circ} 18.838$ ), el servicio del transporte público (artículo $3^{\circ}$ de la Ley $\mathrm{N}^{\circ}$ 18.696), la inscripción de vehículos motorizados (artículo 43 de la Ley del tránsito), la prestación de salud privada (artículo $7^{\circ}$ de la Ley $\mathrm{N}^{\circ} 18.933$ ), las controversias generadas en los procesos de licitación pública destinadas a la compraventa de bienes muebles o servicios por el Estado (artículo 22 ss. de la Ley $\mathrm{N}^{\circ} 19.886$ ), la operación de privados de los servicios de electricidad y agua potable (artículo 19 de la Ley $\mathrm{N}^{\circ} 18.410$ y 13 de la Ley $\mathrm{N}^{\circ} 18.902$, respectivamente), el establecimiento de la calidad de indígena de una persona (artículo $3^{\circ}$ de la Ley $\mathrm{N}^{\circ} 19.253$ ) y el acceso a la información pública (artículo 28 al 30 de la Ley $\mathrm{N}^{\circ} 20.285$ ), por nombrar algunos de los procesos más relevantes y conocidos.

${ }^{19}$ CARMONA SANTANDER, Carlos, El contencioso administrativo entre 1990-2003, en Ferrada Bórquez, Juan Carlos (coordinador), La Justicia administrativa (Santiago de Chile, LexisNexis, 2005), p. 204.

${ }^{20}$ Aróstica Maldonado, Iván, cit. (n. 7), p. 85. 
Ahora bien, estos procesos contenciosos administrativos especiales operan, como se puede observar, en diversos ámbitos, concentrándose sin embargo con mayor claridad en el ámbito de los sectores económicos regulados ${ }^{21}$, en que el impacto de la actividad administrativa, los derechos o intereses involucrados y la relevancia de los actores privados, parecen mover al legislador al establecimiento de un proceso y un tribunal especial en estas materias. En este sentido se ha ido configurando una justicia administrativa especializada, con tribunales y procesos diferenciados que cautelan de mejor forma, más eficiente y eficazmente, ciertos derechos e intereses, en desmedro de otros de menor impacto social.

Por otro lado, en cuanto a las características de estos procesos especiales, la verdad es que es difícil construir una tipología muy ordenada de éstos, atendido la diversidad de reglas que ha dado el legislador en esta materia. Así ya desde su denominación (reclamación, apelación, recurso o demanda), la tramitación que debe seguir la demanda (ordinaria, sumaria, proceso de protección, tramitación incidental o sin forma de juicio), los plazos de interposición de ésta $(5,10,15,30$ o 60 días), las reglas probatorias que siguen (ya sea en cuanto al término probatorio, los medios de prueba y la valoración de éstos) y el contenido mismo de la sentencia (anulatoria, condenatoria o reparatoria), denotan una pluralidad y heterogeneidad difícilmente sistematizable.

Sin perjuicio de lo anterior, y sin que ello implique una caracterización general de estos procesos, pareciera existir en el último tiempo una cierta tendencia a aplicar como procedimiento general el dispuesto para el recurso de protección en el auto acordado dictado por la Corte Suprema en $1992^{22}$, ya sea haciendo referencia explícita a éste o diseñando un procedimiento muy similar a aquel. Este es el caso de los reclamos o recursos establecidos para la revisión de la decisión administrativa en materia municipal (artículo 141 de la Ley orgánica constitucional de municipalidades), telecomunicaciones (artículo 30 A de la Ley general de telecomunicaciones), salud privada (artículo $7^{\circ}$ de la Ley $\mathrm{N}^{\circ} 18.933$ ), televisión (artículo 27 de la Ley $\mathrm{N}^{\circ} 18.838$ ) y de acceso a la información pública (artículo 30 de la Ley $\mathrm{N}^{\circ} 20.285$ ), por nombrar solo algunos ejemplos.

En este sentido, se establece un procedimiento concentrado, breve y sumario, en el que la etapa de discusión se limita al recurso, reclamación o demanda del particular y la contestación del órgano administrativo recurrido -deno-

\footnotetext{
${ }^{21}$ Ibíd., p. 208.
}

${ }^{22}$ Auto Acordado de la Corte Suprema sobre tramitación del recurso de protección de garantías constitucionales, en DO. de 27 de junio de 1992, modificado por los autos acordados de la misma Corte de 1998 y 2007, en DO. el 9 de junio de 1998 y el 8 de junio de 2007, respectivamente. 
minada en muchos casos informe-, una vista de la causa oral ante la misma Corte y eventualmente un probatorio, que sólo excepcionalmente da lugar el tribunal. Esto limita la posibilidad de discusión del asunto controvertido a los escritos presentados por las partes y la audiencia ante el tribunal, pero careciéndose de una confrontación más fundada de las posiciones jurídicas sustentadas por las partes, especialmente en cuanto al establecimiento de los supuestos de hecho que constituyen la base del ejercicio de la potestad administrativa.

Como se puede observar, el procedimiento establecido en estos casos no tiene una extensión y profundidad acorde, en muchos casos, con la gravedad y entidad de las cuestiones debatidas en juicio, las que por su complejidad requieren en muchos casos un procedimiento de lato conocimiento. Ello hace que un sector de la doctrina plantee que este procedimiento no es el más apto para este tipo de conflictos, ya que privilegia en demasía la concentración y celeridad en el juicio, más que la profundidad en el debate y análisis del $\operatorname{caso}^{23}$.

\section{Los procesos administrativos generales.}

a) El recurso de protección como proceso contencioso admin is trativo. Por otro lado, junto a estos procesos administrativos especiales, existen, como ya se señaló, dos procesos administrativos generales: el recurso de protección y la acción de nulidad de Derecho público.

El primero de éstos, el recurso de protección -que en el Derecho comparado se denomina regularmente "amparo" o "amparo de derechos fundamentales"-, como se sabe, es un proceso urgente de tutela de derechos fundamentales, que tiene por objeto cautelar a todas las personas - privadas y públicas, naturales y jurídicas- en el pleno disfrute de los derechos fundamentales establecidos en la Constitución y que ella misma declara amparables por este mecanismo procesal (artículo 19 y $20 \mathrm{CPol}$.).

Este proceso que, como se sabe, fue creado por el Acta Constitucional $\mathrm{N}^{\circ}$ 3 de 1976 y recogido posteriormente en la Constitución de $1980^{24}$, se ventila directamente ante la Corte de Apelaciones respectiva, sin que sea necesario, como ya se indicó, agotar instancia administrativa o judicial previa. Así, las

${ }^{23}$ Por todos, analizando los inconvenientes de este procedimiento, como del proceso de protección en general, véase: PIERry ARrau, Pedro, Recurso de protección y lo contencioso administrativo, en Revista de Derecho de la Universidad de Concepción 44 (1977) 165, p. 17; y, posteriormente, del mismo autor: Conferencia inaugural: Lo contencioso administrativo y el recurso de protección, en Revista de Derecho de la Universidad Católica de Valparaiso, 14 (1991-1992), p. 159.

${ }^{24}$ Por todos, véase: Soto Kloss, Eduardo, El recurso de protección. Orígenes, doctrina y jurisprudencia (Santiago, Editorial Jurídica de Chile, 1982), pp. 23 ss. 
personas solicitan directamente al tribunal el amparo o protección de alguno de sus derechos fundamentales, los que se pueden haber visto amenazados, privados o perturbados por actos u omisiones ilegales o arbitrarias de cualquier persona, órgano u organización pública o privada.

Su procedimiento, como ya se señaló, está regulado, curiosamente ${ }^{25}$, en una norma reglamentaria emanada de la propia Corte Suprema -Auto Acordado de 1992- y dispone tanto el plazo para recurrir, la tramitación ante la Corte de Apelaciones respectiva y la Corte Suprema, el contenido de la sentencia y la ejecución de la misma. Entre estos aspectos vale destacar el breve plazo dispuesto para su interposición (treinta días corridos), su tramitación breve y sumaria ante la Corte de Apelaciones respectiva (cuestión a la que ya se aludió en el punto anterior), resolución en cuenta, por regla general, de la apelación que conoce la Corte Suprema, y establecimiento de mecanismos compulsivos directos para la ejecución.

Como se puede observar, este es un proceso excepcional, de características sumarísimas y urgente, que solo pretende amparar de forma rápida y expedita a los particulares, frente a actos u omisiones que afecten sus derechos fundamentales. Sin embargo, en el ámbito administrativo, este proceso ha jugado desde un comienzo (1976) como un verdadero contencioso administrativo general $^{26}$, ya que ha sido utilizado por los operadores jurídicos como un mecanismo rápido de impugnación de actos u omisiones ilegales o arbitrarias de los órganos de la Administración del Estado, solicitando indirectamente la anulación de los mismos. Así, frente a actuaciones de un órgano de la Administración del Estado que un particular considere ilegales o arbitrarias, éste solicitará directamente a la Corte de Apelaciones respectiva el amparo constitucional de sus derechos, consecuencia de lo cual, normalmente, llevará envuelto, si cabe, la nulidad del acto impugnado ${ }^{27}$.

Ahora bien, como este proceso requiere, para su procedencia, la afectación de alguno de los derechos fundamentales establecidos en la Constitución, el particular deberá establecer una vinculación entre la actuación ilegal o arbi-

${ }^{25}$ Digo curiosamente, ya que a partir de lo dispuesto en el artículo $19 \mathrm{~N}^{\circ} 3$, párrafo $5^{\circ}$ de la Constitución, pareciera haber una reserva de ley para la regulación de los procesos judiciales. Sin embargo, el proceso judicial más relevante del sistema, el que ampara los derechos fundamentales de las personas, tiene una regulación reglamentaria emanada de la propia Corte Suprema.

${ }^{26}$ Pierry Arrau, Pedro, El recurso, cit. (n. 21), p. 177.

${ }^{27}$ Para analizar, la forma como este proceso de tutela urgente de derechos fundamentales ha derivado en un contencioso administrativo, lo que encuentra su fundamento en su propia creación, véase: Ferrada BórQuez, Juan Carlos, El recurso de protección como mecanismo de control contencioso administrativo, en FERRADA BóRQUEZ, Juan Carlos (coordinador), La justicia administrativa (Santiago, LexisNexis, 2005), pp. 129-164. 
traria y la privación, perturbación o amenaza de alguno de esos derechos, lo que en algunos casos será relativamente complejo. En este sentido, la propia Corte Suprema ha señalado expresamente que "es requisito indispensable de la acción de protección la existencia de un acto u omisión ilegal -esto es, contrario a la ley-o arbitrario-producto del mero capricho de quien incurre en él-y que provoque alguna de las situaciones que se han indicado, afectando una o más de las garantías constitucionales protegidas", considerando, en este caso concreto, que ello no se advierte, aunque la ilegalidad del acto pueda establecerse"28.

En este contexto, será usual que los operadores jurídicos utilicen algunos de estos derechos, como la igualdad ante la ley, el debido proceso o la prohibición de comisiones especiales y la propiedad sobre bienes incorporales (artículo 19 numerales 2, 3, y 24 CPol., respectivamente), como cláusulas abiertas de cobertura, tratando, a veces forzadamente, de enmarcar la actuación administrativa como perturbadora de alguno de ellos ${ }^{29}$.

Así es particularmente interesante lo que ha ocurrido con la interdicción de las comisiones especiales y el derecho de propiedad en la jurisprudencia de nuestra Corte. En el primer caso, la Corte ha interpretado esta cláusula de una manera amplísima, incorporando en ella el principio de legalidad de la actividad administrativa y la proscripción de la autotutela administrativa, yendo mucho más allá de la garantía del juez natural que esta norma constitucional establece ${ }^{30}$. En cambio, en el segundo, el derecho de propiedad, la Corte ha evolucionado desde una concepción amplia de cobertura de toda ventaja o beneficio personal a un concepto más estricto de verdadero "bien incorporal”, limitando los casos objeto de esta protección constitucional ${ }^{31}$.

Precisamente esta última circunstancia, es decir, la exigencia de encontrar-

${ }^{28}$ Sentencia de la Corte Suprema, "I. Municipalidad de Penco con Contraloría Regional del Bío-Bío", rol N 1695/2008, de 29 de abril de 2008.

${ }^{29}$ Ferrada Bórquez, Juan Carlos, cit. (n. 25), pp. 152-153.

${ }^{30}$ En este sentido son muy interesantes las Sentencias de la Corte Suprema sobre las facultades fiscalizadoras de la Dirección del Trabajo, sobre todo a propósito de la aplicación de la Ley de Subcontratación. Entre otras, "Corporación Nacional del Cobre de Chile con Dirección del Trabajo”, rol N 953/2008, de 12 de mayo de 2008. Sin embargo, también podemos encontrar sentencias en contra de la misma Corte, estableciendo la regularidad de la actividad administrativa fiscalizadora de la Dirección del Trabajo, reconociéndole a ésta carácter administrativo y no jurisdiccional, rechazando por tanto el recurso judicial, en "Espinoza Rojas con Inspección Provincial del Trabajo de Rancagua”, rol N³595/2008, de 6 de agosto de 2008.

${ }^{31}$ En este sentido es interesante analizar la jurisprudencia generada en la Corte $\mathrm{Su}$ prema sobre el empleo público, en que pese a haber afirmado en un principio el derecho de propiedad sobre él, hoy se ha uniformado en el sentido contrario, negando este derecho, sobre la base de no reconocerlo un bien incorporal técnicamente hablando. Ver, por todas, la reciente Sentencia de la Corte de Apelaciones de Santiago, confirmada por la Corte Suprema, "Monroy Albornoz y otro con General Director de Carabineros de 
se ante una verdadera afectación de un derecho fundamental específico, y no solamente la presencia de un acto u omisión ilegal de la Administración del Estado, constituye una limitación relevante de este proceso de tutela de derechos fundamentales como contencioso administrativo, lo que obviamente es consecuencia del objeto o finalidad del mismo. Ello restringe severamente la utilidad del recurso de protección como proceso contencioso administrativo, replanteando en el Derecho chileno la necesidad de configurar un contencioso administrativo general.

b) El proceso de nulidad de Derecho público. Por su parte, la denominada "acción de nulidad de Derecho público", es el otro proceso administrativo general dispuesto en el ordenamiento jurídico chileno para el control de la actividad administrativa.

Este es un proceso ordinario, con fundamento directo en la propia Constitución (artículo 6 y $7^{32}$ ) -aunque originalmente en el artículo 4 de la Constitución de 1925, con su antecedente en el artículo 160 de la Constitución de $1833^{33}$-, que no tiene desarrollo legislativo y cuya construcción ha sido fruto de la construcción doctrinal y jurisprudencial ${ }^{34}$. En efecto, la nulidad de Derecho público ha sido formulada como una sanción de ineficacia dispuesta en la Constitución para los actos de los órganos del Estado que contravienen el ordenamiento jurídico chileno, y cuya tramitación se sujeta a las reglas del juicio ordinario civil, procedimiento de lato conocimiento ${ }^{35}$.

Chile", rol N ${ }^{\circ} 1188 / 2009$, de 31 de marzo de 2010, confirmado por la Corte Suprema el 10 de junio de 2010.

${ }^{32} \mathrm{El}$ artículo 6 CPol. señala: "Los órganos del Estado deberán someter su acción a la Constitución y a las normas dictadas conforme a ella, y garantizar el orden institucional de la República. Los preceptos de esta Constitución obligan tanto a los titulares o integrantes de dichos órganos como a toda persona, institución o grupo. La infracción de esta norma generará las responsabilidades y sanciones que determine la ley". Por su parte, el artículo 7 dispone: "Los órganos del Estado actúan válidamente previa investidura regular de sus integrantes, dentro de su competencia y en la forma que prescribe la ley. Ninguna magistratura, ninguna persona ni grupo de personas pueden atribuirse, ni aún a pretexto de circunstancias extraordinarias, otra autoridad o derechos que los que expresamente se le hayan conferido en virtud de la Constitución o las leyes. Todo acto en contravención a este artículo es nulo y originará las responsabilidades y sanciones que la ley señale".

${ }^{33}$ Bernaschina, Mario, Bases jurisprudenciales para una teoría de las nulidades administrativas, en Boletín del seminario de Derecho Público de la Escuela de Ciencias Jurídicas y Sociales de la Universidad de Chile, 18 (1949) 45-48, pp. 548-559.

${ }^{34}$ Véase, en este sentido, por todos: Soto KLoss, Eduardo, La nulidad de Derecho público en el derecho chileno, en Revista de Derecho Público, 47-48 (1990), pp. 11-25; y Fiamma Olivares, Gustavo, Acción constitucional de nulidad y legitimación activa objetiva, en Revista de Derecho Público, 49 (1991), pp. 91-98.

${ }^{35}$ Soto KLoss, Eduardo, Derecho administrativo. Bases fundamentales (Santiago de Chile, Editorial Jurídica, 1996), II, p. 192. 
Este proceso, según la construcción doctrinal más citada ${ }^{36}$, tiene por objeto perseguir la nulidad del acto administrativo que contraviene el ordenamiento jurídico chileno, estableciendo además las responsabilidades civiles consiguientes, las cuales son establecidas por el tribunal en la misma sentencia judicial. Así, a través de este proceso, los particulares persiguen restablecer el imperio del Derecho y satisfacer sus propios derechos e intereses, siendo utilizado -tomando como referencia la terminología francesa clásica- como contencioso anulatorio y de plena jurisdicción al mismo tiempo.

Sin embargo, este proceso presenta variadas dificultades de configuración, tanto en sus aspectos substantivos como procesales. Por un lado, en lo sustantivo, si bien esta formulado como un contencioso administrativo anulatorio general, la jurisprudencia ha ido acotando las causales que permiten su ejercicio, reduciéndolo a los tres elementos que menciona el artículo 7 inciso $1^{\circ} \mathrm{CPol} .:$ competencia, investidura regular y formalidades establecidas por la ley ${ }^{37}$. Así, bajo esta perspectiva, solo en la medida que se la irregularidad administrativa conlleve la infracción de alguno de esos elementos definidos por la Constitución se daría lugar a la sanción de nulidad establecida en ésta, lo que dejaría sin cobertura otras irregularidades, incluso de mayor gravedad, que no configuran técnicamente alguno de esos supuestos.

Por otro, se ha discutido arduamente sobre el carácter prescriptible o no de la acción de nulidad de Derecho público, lo que se ha zanjado finalmente, por ahora, en la afirmación de la imprescriptibilidad de ésta, pero la prescripción de las acciones patrimoniales asociadas a ella. Este criterio que ha venido sosteniendo invariablemente la Corte Suprema desde fines del año $2000^{38}$, ha generado un desincentivo a la utilización de este mecanismo procesal, ya que en la mayoría de los casos la nulidad perseguida por los actores de actos estatales irregulares de antigua data, tenía la intención de obtener la reparación patrimonial derivado del mismo, y no sólo el interés por cautelar la corrección de la actividad estatal. .

En cuanto a los aspectos procesales, las dificultades que presenta este proceso derivan de la propia aplicación de las normas procesales civiles a este contencioso administrativo, las que en muchas ocasiones no se adaptan a las

${ }^{36}$ Véase, por todos: Soto KLoss, Eduardo, La nulidad, cit. (n. 29), pp. 19 ss.

${ }^{37}$ Bermúdez Soto, Jorge, El principio de legalidad y la nulidad de Derecho público en la Constitución Politica. Fundamentos para la aplicación de una solución de Derecho común, en Revista de Derecho Público, 70 (2009), pp. 280 ss.

${ }^{38} \mathrm{La}$ sentencia clave en esta materia, es la sentencia de la Corte Suprema, "Aedo con Fisco”, rol N 852/2000, de 27 de noviembre de 2000, en que precisamente se afirmó la distinción entre la acción de nulidad de derecho público, de carácter imprescriptible, y las acciones patrimoniales que pudieran estar vinculadas, las que son prescriptibles, como todas las demás acciones civiles. 
características de este tipo de procesos. Así, los problemas que ha generado la identificación de los legitimados activos y la aplicación de las medidas cautelares han sido dos de los más relevantes en el último tiempo.

En relación al primero, la legitimación activa para accionar la nulidad de Derecho público, ésta se ha construido sobre la idea de la titularidad de derechos e intereses legítimos, siguiendo en ello a la doctrina constitucional y procesal española e italiana. Sin embargo, nuestra doctrina y jurisprudencia ha identificando estos intereses con una categoría procesal y no sustancial, limitando finalmente la legitimación a la concurrencia de un derecho subjetivo que sostenga el interés para actuar en juicio ${ }^{39}$. Así los intereses han carecido en la práctica de reconocimiento como posición legitimante en esta materia, exigiendo la titularidad de un derecho para hacer procedente la demanda de nulidad de Derecho público.

En cuanto a lo segundo, las medidas cautelares, se ha hecho una aplicación supletoria de las normas existentes en esta materia en el Código de Procedimiento Civil, utilizando lamentablemente la misma lógica civil y sin comprender la relevancia y centralidad de éstas en la justicia administrativa. Así la propia insuficiencia de las medidas cautelares típicas o nominadas del procedimiento civil (artículo 290 CPC.), en relación al proceso administrativo, han supuesto, en principio, un desafío al otorgamiento de la medida cautelar ordinaria de la justicia administrativa, la suspensión del acto administrativo impugnado. Ésta medida cautelar prototípica en el Derecho comparado no se encuentra expresamente reconocida en la normativa procesal civil, lo que ha llevado a solicitarla en el marco de la medida cautelar de “prohibición de celebrar actos y contratos" contemplada en el numeral $4^{\circ}$ del artículo 290 CPC. o bien como medida cautelar innominada admitida en el artículo 298 del mismo Código $^{40}$.

A lo anterior se añade la renuencia de los jueces a conceder esta medida suspensiva, ya sea por el carácter innominado de las mismas, como la falta de identificación de esta medida suspensiva con alguna de las nominadas expresamente en el Código. A lo anterior se añade la exigencia de altos estándares de probabilidad del daño patrimonial y de apariencia de buen derecho para la concesión de la medida, lo que hace prácticamente imposible su procedencia.

${ }^{39}$ En este sentido, véase: Ferrada BórQuez, Juan Carlos, Nuevas restricciones a la nulidad de Derecho público como proceso administrativo: una jurisprudencia interesante, pero inconsistente, en Anuario de Derecho Público de la Universidad Diego Portales, 1 (2010), pp. 189 ss.

${ }^{40}$ Véase, en este sentido: Bordalí Salamanca, Andrés - Ferrada Bóreuez, Juan Carlos, La tutela cautelar en la justicia administrativa, en Estudios de justicia administrativa (Santiago de Chile, LexisNexis, 2008), pp. 204-207. 
Sin duda estas objeciones plantean serios inconvenientes para la utilización práctica de la nulidad de Derecho público como proceso contencioso administrativo general, aunque es evidente que presenta las mejores aptitudes para afirmarse como tal. La doctrina y jurisprudencia podrían colaborar mucho en esta materia, al menos mientras no se regule en forma más eficiente esta materia.

\section{La relación jurídica entre procesos administrativos especiales y genera- les.}

Una vez enumerados y descritos sucintamente los procesos administrativos especiales y generales en el Derecho chileno, una cuestión relevante a resolver es establecer la relación jurídica que existe entre éstos, ya que todos ellos forman parte del conjunto de mecanismos de impugnación de los actos administrativos.

En este contexto, una primera cuestión es dilucidar como operan estos procesos administrativos especiales entre sí, particularmente atendido la pluralidad y heterogeneidad imperante. Sobre ello no parece haber dudas que éstos se excluyen unos a otros, atendido la particularidad o especificidad del objeto pedido y los alcances establecidos en la regulación especial dispuesta para cada caso. En otras palabras, cada uno de estos procesos administrativos especiales se aplica a una materia específica, lo que impide, en principio, que sean aplicables otros dispuestos para otras materias.

Sin embargo, hay ciertos ámbitos donde la especialidad opera en dos ámbitos convergentes: en relación a la autoridad emisora del acto y la materia específica de que trata el acto administrativo impugnable. Así, por ejemplo, en el ámbito municipal, concurrirían, en principio, en el reclamo de ilegalidad municipal (artículo 141 de la Ley orgánica constitucional de municipalidades) y el reclamo de ilegalidad de urbanismo y construcción (artículo 12 y 118 de la Ley general de urbanismo y construcción) -aunque este último sería más propiamente un recurso administrativo-, ya que ambos estarán destinados a impugnar un acto administrativo municipal en materia de urbanismo. En este contexto, la jurisprudencia ha admitido la procedencia de ambos, sin excluir uno a otro por especialidad de la materia, aunque pareciera evidente que el segundo tendría un grado de especialidad mayor en el caso de los actos administrativos municipales relacionado con el urbanismo o la construcción.

Por otro lado, en cuanto a la relación de estos procesos especiales y los procesos generales, la cuestión es más compleja. La opinión de la doctrina más consolidada es, aparentemente, que estos últimos -los procesos generalesoperan no sólo como mecanismos residuales o supletorios de los primeros -los procesos especiales-, sino como procesos alternativos o complementa- 
rios $^{41}$. Así, bajo este enfoque, los particulares podrían utilizar, para impugnar una acción u omisión administrativa, el procedimiento especial dispuesto por el ordenamiento jurídico, o el o los generales disponibles, quedando a criterio o decisión del reclamante o demandante la alternativa seguida.

Este criterio ha sido respaldado por la jurisprudencia, particularmente a propósito de la acción de nulidad de Derecho público, ya que atendido el carácter imprescriptible que se le ha reconocido a ésta, los particulares han utilizado el proceso especial para impugnar el acto administrativo, y rechazada esa vía o estimada más gravosa por la parte, ha incoado el proceso general señalado ${ }^{42}$. Ello ha permitido una doble impugnación del acto administrativo, lo que genera no pocos problemas en relación a la cosa juzgada y a la seguridad jurídica de las resoluciones judiciales.

Algo parecido ha ocurrido con el recurso de protección, ya que este último, como ya se mencionó, por expresa disposición constitucional, opera "sin perjuicio de los demás derechos que pueda hacer valer anta la autoridad o los tribunales correspondientes”. Esto permitiría, según la interpretación mayoritaria de la doctrina y la jurisprudencia, el ejercicio de las acciones judiciales específicas y, aún del propio proceso de nulidad de Derecho público, en forma paralela o subsidiaria al recurso de protección, lo que llevaría también envuelto los problemas de seguridad jurídica antes apuntados. No obstante, este criterio también ha encontrado algunas restricciones en un sector de la jurisprudencia, ya que utilizando el criterio de especialidad ha declarado su inhibición en el conocimiento de algunas controversias administrativas específicas, por existir un proceso especial para dirimir las controversias en esa materia ${ }^{43}$, lo que es más claro y categórico en el caso de procesos que se encuentran pendientes de resolución ${ }^{44}$.

Sin embargo, a mi juicio, la relación jurídica entre procesos especiales y generales en el ordenamiento jurídico chileno no se resuelve de forma general ni por un criterio de supletoriedad, ni especialidad, al menos en relación a los dos procesos generales antes apuntados. Así, en el caso de la acción de nulidad de Derecho público y los procesos especiales, es evidente que estos últimos

${ }^{41}$ Por todos: Aróstica Maldonado, Iván, Los contenciosos, cit. (n. 7), p. 86.

${ }^{42}$ Véase, entre otras: la sentencia de la Corte Suprema, "Clonexpress Computación Limitada y otro con Director de Obras Municipales de Viña del Mar y otros”, rol N ${ }^{\circ}$ 561/2007, de 12 de agosto de 2008.

${ }^{43}$ En esta materia véase, entre otras, la sentencia de la Corte Suprema "Inmobiliaria Aseg-Grevia Limitada con Ilustre Municipalidad de Independencia”, rol $\mathrm{N}^{\circ}$ 2991/2008, de 20 de octubre de 2008.

${ }^{44}$ Sentencia de la Corte de Apelaciones de Temuco, confirmada por la Corte Suprema, "Constructora Wörner S.A. en contra de la Dirección Regional de Arquitectura MOP, Novena Región”, rol N 11/2010, de 12 de febrero de 2010. 
-en aquellos casos en que se persigue la nulidad o invalidez del acto administrativo- excluyen la primera -la acción de nulidad de Derecho público-, ya que el objeto pedido es el mismo - la nulidad o ilegalidad del acto-, por lo que debe operar un criterio de especialidad. Lo contrario llevaría a la existencia de vías paralelas de impugnación administrativa del acto, lo que además de absurdo e ineficiente, desde el punto de vista del ejercicio de la actividad jurisdiccional, podría dar lugar a resoluciones judiciales contradictorias

Por otro lado, en cuanto a la vinculación entre recurso de protección y procesos especiales, la situación es algo distinta, ya que no operaría una relación de generalidad-especialidad, como lo ha sostenido la doctrina y un sector de la jurisprudencia, sino derechamente de exclusión en relación al objeto pedido. Así, sería procedente el recurso de protección, como proceso de impugnación del acto administrativo, en aquellos casos en que se pretende la tutela de un derecho fundamental de aquellos especialmente amparados por esta vía y el acto impugnado supone una privación, perturbación o amenaza de los mismos. En cambio será aplicable el proceso especial en aquellos casos en que se discuta la mera legalidad o regularidad del acto administrativo en general, o la protección de un derecho no fundamental o un interés legítimo -en los casos que proceda-, pero sin que esté comprometido directa e inmediatamente un derecho fundamental del particular.

Lo anterior también operaría en el caso del recurso de protección y el proceso de nulidad de Derecho público, ya que ellos no operarían de forma subsidiaria, ni complementaria, sino excluyente, en relación al objeto pedido por el actor. Así, si lo solicitado por el actor es el amparo de un derecho fundamental, el proceso que corresponde utilizar es el recurso de protección. En cambio, si lo perseguido es la impugnación de la validez del acto, protegiendo un derecho o interés del actor, el proceso elegido debe ser la nulidad de Derecho público, ya que no hay en juego derecho fundamental comprometido en la especie. Este y no otro, por lo demás, aplicado en materia civil general, en que los actores utilizan los procesos civiles no como subsidiarios del recurso de protección, sino como vías idóneas, atendido el objeto pedido en cada caso.

\section{CONCLUSIONES}

De lo expuesto en las páginas precedentes se pueden extraer algunas conclusiones que paso a formular:

a) Los procesos judiciales a través de los cuales se desarrolla la justicia administrativa en el ordenamiento jurídico chileno son muy heterogéneos, existiendo una gran dispersión para impugnar los actos de la Administración del Estado y tutelar los derechos o intereses de los particulares. 
b) Existe una tendencia muy acentuada en las últimas décadas en la construcción de procesos especiales para controlar la actividad administrativa, lo que se ha desarrollado particularmente en ámbitos sensibles de la actividad económica. Ello ha dado lugar a una justicia especializada rodeada de ciertos privilegios, en relación a los demás procesos impugnatorios de actos administrativos ordinarios.

c) Se aprecia un cierto abandono del legislador en la construcción de un sistema de justicia administrativa general, dejándose entregado a la jurisprudencia la definición de sus características y elementos, lo que presenta desarrollos irregulares e imprecisos. Esto es especialmente relevante en materia de nulidad de Derecho público, proceso que se ha consolidado como el contencioso administrativo general, pero cuyas dificultades de articulación han impedido su desarrollo adecuado.

d) Producto de lo anterior, la doctrina pareciera estar concentrada en el último tiempo en el estudio y análisis de estos procesos administrativos especiales, tratando de consolidar un sistema eficaz de control de la actividad administrativa y protección de los derechos o intereses de los particulares. Esto genera desarrollos desiguales en el control de la actividad administrativa, privilegiándose los ámbitos en los que intervienen actores políticos y económicos relevantes, en desmedro de las controversias en que intervienen los ciudadanos en general.

\section{Bibliografía}

ARóstica Maldonado, Iván, Los contenciosos administrativos especiales en la legislación chilena, en Ius Publicum, 20 (2008).

Bermúdez Soto, Jorge, Derecho administrativo general (Santiago de Chile, Abeledo Perrot - Legal Publishing, 2010).

Bermúdez Soto, Jorge, El principio de legalidad y la nulidad de Derecho público en la Constitución Politica. Fundamentos para la aplicación de una solución de Derecho común, en Revista de Derecho Público, 70 (2009).

Bernaschina, Mario, Basesjurisprudencialespara una teoria de las nulidades administrativas, en Boletín del seminario de Derecho Público de la Escuela de Ciencias Jurídicas y Sociales de la Universidad de Chile, 18 (1949) 45-48.

Bordalí Salamanca, Andrés - Ferrada Bórguez, Juan Carlos, La tutela cautelar en la justicia administrativa, en Estudios de justicia administrativa (Santiago de Chile, LexisNexis, 2008).

Carmona Santander, Carlos, El contencioso administrativo entre 1990-2003, en Ferrada Bórquez, Juan Carlos (coordinador), La justicia administrativa (Santiago de Chile, LexisNexis, 2005).

Cordero Vega, Luis, La supletoriedad en la Ley de Bases de Procedimiento Administrativo, en Acto y procedimiento administrativo (Valparaíso, Ediciones Universitarias de Valparaíso, s. d).

FERRADA BóRQuez, Juan Carlos, El recurso de protección como mecanismo de control 
contencioso administrativo, en FERRAda BóRQUEZ, Juan Carlos (coordinador), La justicia administrativa (Santiago de Chile, LexisNexis, 2005).

Ferrada Bórquez, Juan Carlos, Las potestades y privilegios de la Administración Pública en el régimen administrativo chileno, en Revista de Derecho de la Universidad Austral de Chile, 20 (2007) 2.

Ferrada Bórquez, Juan Carlos, Nuevas restricciones a la nulidad de Derecho público como proceso administrativo: una jurisprudencia interesante, pero inconsistente, en Anuario de Derecho Público de la Universidad Diego Portales, 1 (2010).

Fiamma Olivares, Gustavo, Acción constitucional de nulidad y legitimación activa objetiva, en Revista de Derecho Público, 49 (1991).

García de Enterría, Eduardo - Fernández, Tomás Ramón, Curso de Derecho administrativo (7º edición, reimpresión, Madrid, Civitas, 1996), I.

García de Enterría, Eduardo - Fernández, Tomás-Ramón, Curso de Derecho administrativo ( $4^{\circ}$ edición, reimpresión, Madrid, Civitas, 1997), II.

GonzÁlez Pérez, Jesús, Derecho procesal administrativo (Madrid, Civitas, 2000).

Parejo Alfonso, Luciano, Derecho administrativo, (Barcelona, Ariel Derecho, 2003).

Pierry Arrau, Pedro, Conferencia inaugural: Lo contencioso administrativo y el recurso de protección, en Revista de Derecho de la Universidad Católica de Valparaíso, 14 (1991-1992).

Pierry Arrau, Pedro, Recurso de protección y lo contencioso administrativo, en Revista de Derecho de la Universidad de Concepción 44 (1977) 165.

Sánchez Morón, Miguel, Recursos administrativos, en Leguina Villa, Jesús SÁnchez Morón, Miguel (directores), La nueva Ley de régimen jurídico de las administraciones públicas y del procedimiento administrativo común (Madrid, Tecnos, 1993).

Schmidt-Assmann, Eberhard, La teoría general del Derecho administrativo como sistema (Madrid, INAP - Marcial Pons, 2003).

Sото KLoss, Eduardo, Derecho administrativo. Bases fundamentales (Santiago de Chile, Editorial Jurídica, 1996), II.

Sото KLoss, Eduardo, El recurso de protección. Origenes, doctrina y jurisprudencia (Santiago de Chile, Editorial Jurídica, 1982).

Soтo Kloss, Eduardo, La nulidad de Derecho público en el Derecho chileno, en Revista de Derecho Público, 47-48 (1990).

Vergara Blanco, Alejandro, Eficacia derogatoria y supletoria de la Ley de bases de los procedimientos administrativos, en Acto y procedimiento administrativo (Valparaíso, Ediciones Universitarias de Valparaíso, s.d). 
